\title{
Niflumic acid-sensitive ion channels play an important role in the induction of glucose-stimulated insulin secretion by cyclic AMP in mice
}

\author{
W. Fujimoto • T. Miki • T. Ogura • M. Zhang • Y. Seino • \\ L. S. Satin • H. Nakaya $\cdot$ S. Seino
}

Received: 21 October 2008 / Accepted: 8 February 2009/Published online: 6 March 2009

(C) Springer-Verlag 2009

\begin{abstract}
Aims/hypothesis We have previously reported that glucosestimulated insulin secretion (GSIS) is induced by glucagonlike peptide-1 (GLP-1) in mice lacking ATP-sensitive $\mathrm{K}^{+}$ $\left(\mathrm{K}_{\mathrm{ATP}}\right)$ channels (Kir6. $2^{-/}$mice [up-to-date symbol for Kir6.2 gene is Kcnj11]), in which glucose alone does not trigger insulin secretion. This study aimed to clarify the mechanism involved in the induction of GSIS by GLP-1. Methods Pancreas perfusion experiments were performed using wild-type $\left(\operatorname{Kir} 6.2^{+/+}\right)$or Kir6. $2^{-/-}$mice. Glucose concentrations were either changed abruptly from 2.8 to $16.7 \mathrm{mmol} / \mathrm{l}$ or increased stepwise $(1.4 \mathrm{mmol} / \mathrm{l}$ per step) from 2.8 to $12.5 \mathrm{mmol} / \mathrm{l}$. Electrophysiological experiments were performed using pancreatic beta cells isolated from Kir6. $2^{-/-}$mice or clonal pancreatic beta cells (MIN6 cells) after pharmacologically inhibiting their $\mathrm{K}_{\text {ATP }}$ channels with glibenclamide.
\end{abstract}

\footnotetext{
W. Fujimoto $\cdot$ T. Miki $\cdot$ Y. Seino $\cdot$ S. Seino $(\bowtie)$ Division of Cellular and Molecular Medicine, Kobe University Graduate School of Medicine,

Results The combination of cyclic AMP plus $16.7 \mathrm{mmol} / \mathrm{l}$ glucose evoked insulin secretion in Kir6. $2^{-/}$pancreases where glucose alone was ineffective as a secretagogue. The secretion was blocked by the application of niflumic acid. In $\mathrm{K}_{\text {ATP }}$ channel-inactivated MIN6 cells, niflumic acid similarly inhibited the membrane depolarisation caused by cAMP plus glucose. Surprisingly, stepwise increases of glucose concentration triggered insulin secretion only in the presence of cAMP or GLP-1 in Kir6. $2^{+/+}$, as in Kir6. $2^{-/-}$pancreases.

Conclusions/interpretation Niflumic acid-sensitive ion channels participate in the induction of GSIS by cyclic AMP in Kir6. $2^{-/-}$beta cells. Cyclic AMP thus not only acts as a potentiator of insulin secretion, but appears to be permissive for GSIS via novel, niflumic acid-sensitive ion channels. This mechanism may be physiologically important for triggering insulin secretion when the plasma glucose concentration increases gradually rather than abruptly.

\section{Y. Seino}

Division of Endocrinology and Diabetes,

Nagoya University Graduate School of Medicine,

Nagoya, Japan

\section{S. Seino}

Division of Diabetes, Metabolism and Endocrinology,

Department of Internal Medicine,

Kobe University Graduate School of Medicine,

Kobe, Japan

\section{S. Seino}

Core Research for Evolutional Science and Technology (CREST),

Japan Science and Technology Agency,

Kawaguchi, Saitama, Japan

Present address:

L. S. Satin

Department of Pharmacology,

University of Michigan Medical School,

Ann Arbor, MI, USA 
Keywords cAMP. GLP-1 - Incretin · Insulin secretion · $\mathrm{K}_{\text {ATP }}$ channel $\cdot$ Kir6.2 $\cdot$ Niflumic acid

\begin{tabular}{|c|c|}
\hline \multicolumn{2}{|l|}{ Abbreviations } \\
\hline 8-Br-cAMP & $\begin{array}{l}\text { 8-Bromoadenosine } 3{ }^{\prime}, 5^{\prime} \text {-cyclic } \\
\text { monophosphate sodium salt }\end{array}$ \\
\hline cAMP & Cyclic AMP \\
\hline CFTR & $\begin{array}{l}\text { Cystic fibrosis transmembrane } \\
\text { conductance regulator }\end{array}$ \\
\hline 8-pCPT-cGMP & $\begin{array}{l}\text { 8- } p \text {-Chlorophenylthioguanosine- } 3 \text {, } \\
5^{\prime} \text {-cyclic guanosine monophosphate }\end{array}$ \\
\hline $\begin{array}{l}\text { CRAC } \\
\text { channel }\end{array}$ & $\mathrm{Ca}^{2+}$-release-activated $\mathrm{Ca}^{2+}$ channel \\
\hline DPC & $N$-Phenylanthranilic acid \\
\hline GIP & Glucose-dependent insulinotrophic peptide \\
\hline GLP-1 & Glucagon-like peptide 1 \\
\hline GSIS & Glucose-stimulated insulin secretion \\
\hline HPRT & Hypoxanthine phosphoribosyltransferase \\
\hline $\begin{array}{l}\mathrm{K}_{\mathrm{ATP}} \\
\text { channel }\end{array}$ & ATP-sensitive $\mathrm{K}^{+}$channel \\
\hline NMG & $N^{\prime}$-methyl-D-glucamine \\
\hline NSCC & Non-selective cation channel \\
\hline VDCC & Voltage-dependent $\mathrm{Ca}^{2+}$ channel \\
\hline
\end{tabular}

\section{Introduction}

Insulin secretion from pancreatic beta cells is regulated and modulated by a variety of factors including nutrients, hormones and neural inputs. Glucose-stimulated insulin secretion (GSIS) and its potentiation are the fundamental regulatory mechanisms of insulin secretion. According to the current consensus regarding the triggering pathway of GSIS [1-3], an increase in intracellular ATP/ADP by glucose metabolism closes ATP-sensitive $\mathrm{K}^{+}\left(\mathrm{K}_{\text {ATP }}\right)$ channels to depolarise the beta cell membrane and open the voltage-dependent $\mathrm{Ca}^{2+}$ channels (VDCCs), allowing the entry of extracellular $\mathrm{Ca}^{2+}$ that triggers the release of insulin from the beta cell. GSIS is further potentiated by cyclic AMP (cAMP) [4]. cAMP signalling in pancreatic beta cells is activated by incretins such as glucosedependent insulinotrophic peptide (GIP) and glucagon-like peptide-1 (GLP-1), gut hormones secreted upon meal ingestion from enteroendocrine $\mathrm{K}$ cells and $\mathrm{L}$ cells, respectively [5]. The potentiation of insulin secretion by these incretins is characterised by the requirement for a glucose concentration above a certain threshold [6]. Because of this key property of GLP-1, its analogues, as well as inhibitors of its degradation, have been recognised as being useful drugs to treat type 2 diabetes mellitus, since they should have a low risk of producing hypoglycaemia [4]. However, the detailed mechanism of the glucose dependence of incretin action in eliciting insulin secretion has not been elucidated.

The importance of the $\mathrm{K}_{\mathrm{ATP}}$ channel for GSIS has been shown directly in studies of $\mathrm{K}_{\text {ATP }}$ channel-deficient Kir6. $2^{-/-}$(up-to-date symbol for Kir6.2 gene is Kcnj11) and $\operatorname{Surl}^{-/}$(the up-to-date symbol for SUR1 gene is $A b c c 8)$ mice [7-9]. However, using a pancreatic perfusion system, we recently found to our surprise that incretin pretreatment was able to trigger GSIS in Kir6. $2^{-/-}$mice lacking $K_{\text {ATP }}$ channels [10], suggesting a novel mechanism of glucose sensing which appears to bypass or obviate the need for normal closure of $\mathrm{K}_{\text {ATP }}$ channels by glucose metabolism in Kir6. $2^{+/+}$beta cells.

In the present study, we further investigated the mechanism of incretin-induced glucose responsiveness in insulin secretion. Furthermore, we evaluated the physiological importance of cAMP-induced GSIS in Kir6. $2^{+/+}$mice by applying small, stepwise increases in glucose concentrations in perfusion studies.

\section{Methods}

Animals The Kir6. $2^{-/}$mice were generated as previously described [7]. All animal experiments were performed in accordance with the guidelines of the Kobe University Animal Care Committee.

Reagents 8-Br-cAMP (8-bromoadenosine 3',5'-cyclic monophosphate sodium salt), nifedipine, thapsigargin, niflumic acid, NMG ( $N^{\prime}$-methyl-D-glucamine), 8- $p$-chlorophenylthioguanosine--3',5'-cyclic guanosine monophosphate (8-pCPT-cGMP), SKF96365 and glibenclamide were from Sigma-Aldrich (St Louis, MO, USA). DPC $(N$-phenylanthranilic acid) and carbachol (carbamylcholine chloride) were from Wako (Osaka, Japan). GLP-1 (human, 7-36 amide) was obtained from The Peptide Institute (Osaka, Japan).

Perfusion experiments Perfusion studies of mouse pancreases were performed as previously described [10]. Briefly, overnight $(16 \mathrm{~h})$ fasted male or female mice of 16-30 weeks of age were used. The perfusion protocol began with a 10 min equilibration period with the same buffer used in the initial step shown in the Figures. The flow rate of the perfusate was $1 \mathrm{ml} / \mathrm{min}$.

RT-PCR analysis Total RNA from MIN6 cells (a mouse insulinoma cell line), mouse small intestine and isolated pancreatic islets [7], were subjected to RT-PCR under standardised conditions. PCR primers for mouse hypoxanthine phosphoribosyltransferase (HPRT) and cystic fibrosis 
transmembrane conductance regulator (CFTR) were designed such that the amplified regions spanned an intron in the gene, 5'-TCTTTGCTGACCTGCTGGATT-3' and 5'GGCTTTGTATTTGGCTTTTCC-3', and 5'-TCAGCTGAC CACTTGTCTGA-3' and 5'-CACAGAAGGCTGAGAA CTGT-3', respectively. The PCR condition was as follows: denaturation at $94^{\circ} \mathrm{C}$ for $30 \mathrm{~s}$, annealing at $58^{\circ} \mathrm{C}$ (HPRT) or $52^{\circ} \mathrm{C}$ (CFTR) for $30 \mathrm{~s}$, and extension at $72^{\circ} \mathrm{C}$ for $45 \mathrm{~s}$ over 30 (HPRT) or 35 (CFTR) cycles, respectively.

Electrophysiology Islet cells isolated from $\mathrm{Kir} 6.2^{+/+}$or Kir6. $2^{-/-}$mice were placed in a recording chamber affixed to the stage of an inverted fluorescence microscope (Olympus IX50; Tokyo, Japan) and were continuously superfused with an external solution that contained (in mmol/l) $115 \mathrm{NaCl}, 3 \mathrm{CaCl}_{2}, 5 \mathrm{KCl}, 2 \mathrm{MgCl}_{2}, 10$ HEPES and 11.1 glucose ( $\mathrm{pH}$ 7.2). In perforated-patch experiments, pipettes were filled with a solution that contained (in mmol/l) $28.4 \mathrm{~K}_{2} \mathrm{SO}_{4}, 63.7 \mathrm{KCl}, 11.8 \mathrm{NaCl}, 1 \mathrm{MgCl}_{2}, 20.8$ HEPES, 0.5 EGTA and $0.3 \mathrm{mg} / \mathrm{ml}$ amphotericin $\mathrm{B}(\mathrm{pH} 7.2)$.

MIN6 cells were cultured with medium containing $10 \mu \mathrm{mol} / 1$ glibenclamide for 14 days to pharmacologically inhibit the $K_{\text {ATP }}$ channels of the cells [11]. After this treatment, cells were seeded on glass coverslips and used for electrophysiological experiments. Membrane potentials were recorded in the current clamp mode of the perforated patch-clamp technique as described above. The extracellular solution contained (in mmol/l) $140 \mathrm{NaCl}, 5 \mathrm{KCl}, 2$ $\mathrm{CaCl}_{2}, 1 \mathrm{MgCl}_{2}, 10$ HEPES, 2.8 or 16.7 glucose and $1 \mu \mathrm{mol} / 1$ glibenclamide (pH 7.4).

\section{Results}

ATP and $\mathrm{Ca}^{2+}$ influx through VDCCs are required for the induction of glucose responsiveness by cAMP in Kir6. $2^{--}$ mice To determine whether the glucose responsiveness we observed in Kir6. $2^{-/-}$mice treated with the incretins GLP-1 or GIP is mediated by a cAMP-dependent signalling system, we first examined the action of 8-Br-cAMP, a membranepermeable analogue of cAMP, in evoking GSIS in this model. Treatment with $1 \mathrm{mmol} / 1$ 8-Br-cAMP clearly induced glucose responsiveness in Kir6. $2^{-/}$mice, as in the case of GLP-1 or GIP, although the degree of insulin secretory response was less with GIP than with GLP-1 [10] (Fig. 1ac). We found that in the presence of 8-Br-cAMP, stimulation with $16.7 \mathrm{mmol} / \mathrm{l}$ glucose elicited a small, transient drop in secretion, followed by an apparent rise in Kir6. $2^{-/}$mice (Fig. 1c). The rise in the insulin secretory response to glucose in Kir6. $2^{-/}$mice was delayed by 1-2 min compared with that observed in Kir6. $2^{+/+}$mice $\left(2-3 \mathrm{~min}\right.$ in Kir6. $2^{-/-}$ mice; $<1 \mathrm{~min}$ in $\mathrm{Kir} 6.2^{+/+}$). This result is consistent with the results seen in Kir6. $2^{--}$mice treated with GLP-1 or GIP.
To determine which glucose-derived intracellular metabolite is required for the induction of glucose responsiveness by cAMP in $\mathrm{K}_{\text {ATP }}$ channel-deficient beta cells, ATP production was inhibited by $\mathrm{NaN}_{3}$, an inhibitor of oxidative phosphorylation in mitochondria [12]. $\mathrm{NaN}_{3}$ significantly reduced cAMP-induced GSIS of Kir6. $2^{-/}$mice, while its removal resulted in secretion (Fig. 1d). cAMP-induced GSIS triggered by the removal of $\mathrm{NaN}_{3}$ in Kir6. $2^{-/}$mice also appeared to be delayed by 1-2 min compared with that in Kir6. $2^{+/+}$mice (Fig. 1f). In addition, we adopted a novel protocol in which the pancreases were treated with $\mathrm{NaN}_{3}$ for a longer period (an additional $5 \mathrm{~min}$, Fig. 1e). Using this protocol, the off-response to $\mathrm{NaN}_{3}$ was apparently smaller (peaking at $32 \mathrm{~min}$ in Fig. 1e) than that in Fig. 1d, suggesting that appropriate temporal integration between the triggering and potentiation of secretion by glucose is important in determining the amount of the insulin secretion observed. We also found that longer treatment with $\mathrm{NaN}_{3}$ markedly delayed cAMP-induced GSIS (peaking at $22 \mathrm{~min}$, as in Fig. 1e). GSIS in Kir6. $2^{+/+}$mice was abolished by $\mathrm{NaN}_{3}$ in the absence of 8-Br-cAMP (Fig. 1f), but persisted in the presence of 8-Br-cAMP (Fig. 1f). These results are also compatible with those obtained in Kir6.2 $2^{--}$ mice (Fig. 1e).

To determine whether $\mathrm{Ca}^{2+}$ influx through VDCCs is involved in cAMP-induced glucose responsiveness in Kir6. $2^{-/}$mice, the effect of nifedipine, a well known blocker of L type VDCCs, was evaluated (Fig. 1g). Nifedipine completely blocked 8-Br-cAMP-induced GSIS, suggesting that induction of glucose responsiveness by cAMP is mediated by membrane depolarisation prior to an increase in $\mathrm{Ca}^{2+}$ influx through L type VDCCs. On the other hand, carbachol-induced $\mathrm{Ca}^{2+}$ release from the endoplasmic reticulum elicited insulin secretion without a delay in Kir6. $2^{-/}$mice (Fig. $1 \mathrm{~g}$ ).

To determine whether intracellular $\mathrm{Ca}^{2+}$ release is required for triggering cAMP-induced GSIS in Kir6.2 $2^{-/}$ mice, Kir6. $2^{-/}$pancreases were pretreated with thapsigargin, which drains $\mathrm{Ca}^{2+}$ from the endoplasmic reticulum by blocking sarco/endoplasmic reticulum $\mathrm{Ca}^{2+}$-ATPase [13, 14]. Thapsigargin treatment decreased cAMP-induced GSIS in Kir6. $2^{-/}$pancreases, but did not result in a further delay of the secretory response (Fig. 1h). This result shows that $\mathrm{Ca}^{2+}$ release from the endoplasmic reticulum is not required for the triggering step of insulin secretion by glucose plus cAMP in Kir6. $2^{-/-}$mice, further supporting the hypothesis that membrane depolarisation and consequent $\mathrm{Ca}^{2+}$ influx through VDCCs are required for cAMPinduced GSIS in Kir6. $2^{-/-}$mice.

cGMP-gated channels, CFTR and $\mathrm{Na}^{+}$-permeable nonselective cation channels (NSCCS) do not appear to be required for the induction of cAMP-induced GSIS in 
Fig. 1 8-Br-cAMP-potentiated GSIS by perfusion analysis. a-c Effect of absence (a) and presence $(\mathbf{b}, \mathbf{c})$ of 8 -Br-cAMP on GSIS in Kir6.2 $2^{+/+}$(white circles) and Kir6. $2^{-/-}$(black circles) mice. The glucose concentration $(\mathrm{G})$ was changed from 2.8 to $16.7 \mathrm{mmol} / \mathrm{l}$ as shown. Insulin secretion of Kir6. $2^{-/}$mice in the presence of 8-Br-cAMP is magnified (c). d-f Effect of $\mathrm{NaN}_{3}$ on induction of GSIS by 8 -Br-cAMP in Kir6. $2^{-/-}$mice $(\mathbf{d}, \mathbf{e})$ or on GSIS in Kir6. $2^{+/+}$(g) with (white circles) or without (white triangles) 8-Br-cAMP. Effect of nifedipine (g) or thapsigargin (h) on induction of GSIS by 8-Br-cAMP in Kir6.2 $2^{-/}$mice. In $\mathbf{g}$, the pancreases were stimulated by carbachol (Cch) at the end of perfusion. Means \pm SE of $n=3-7$ mice a

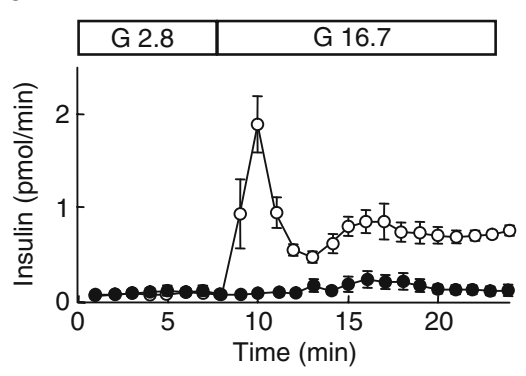

C
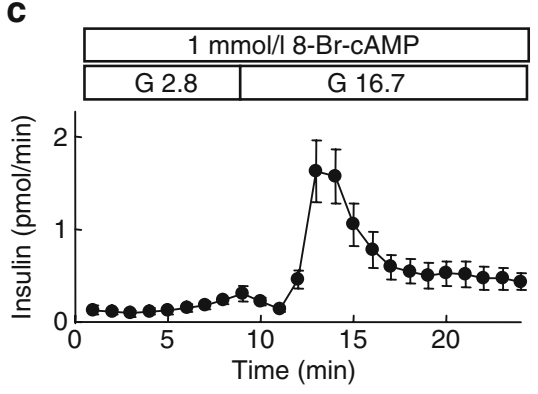

e
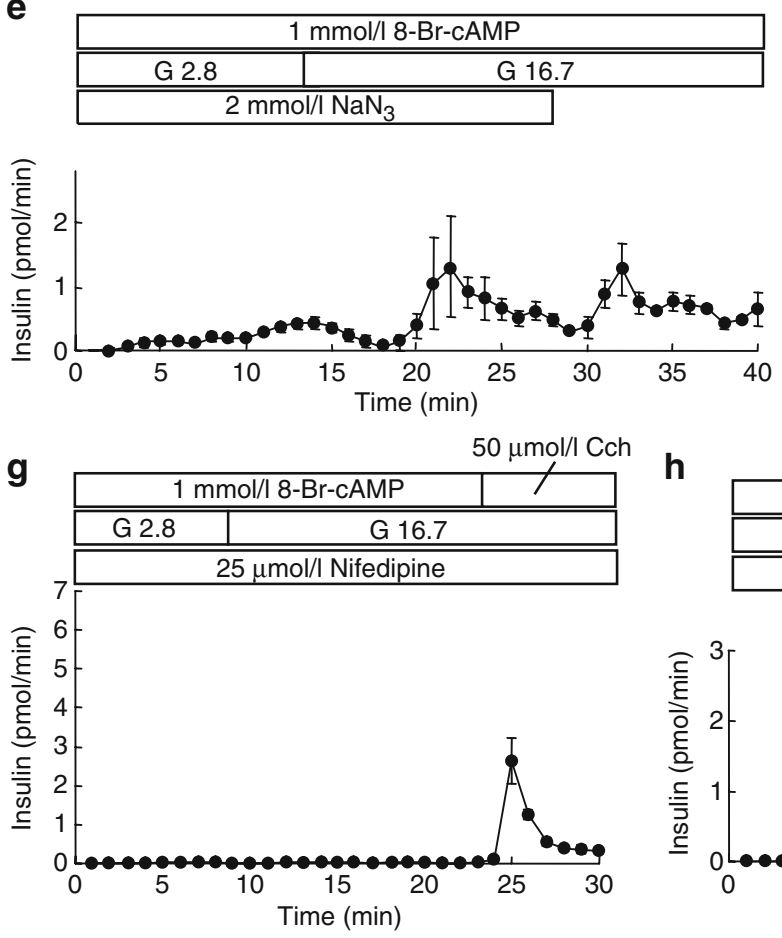

b
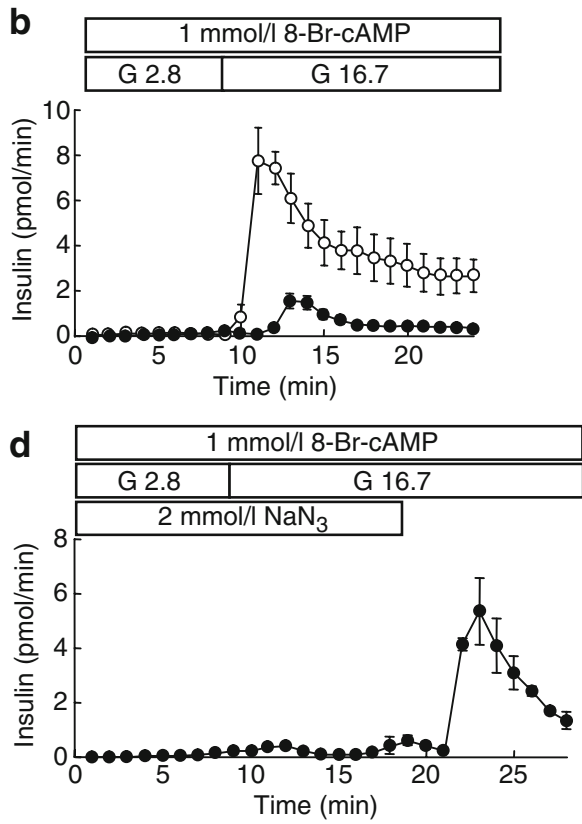

f

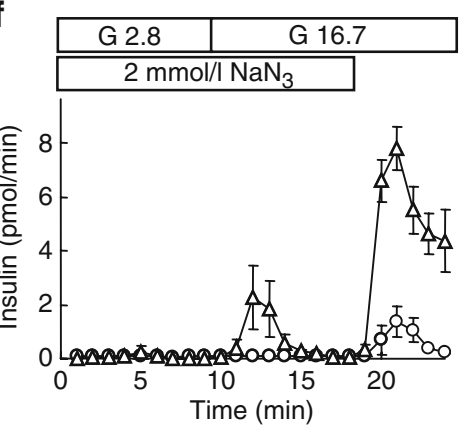

$\mathbf{h}$
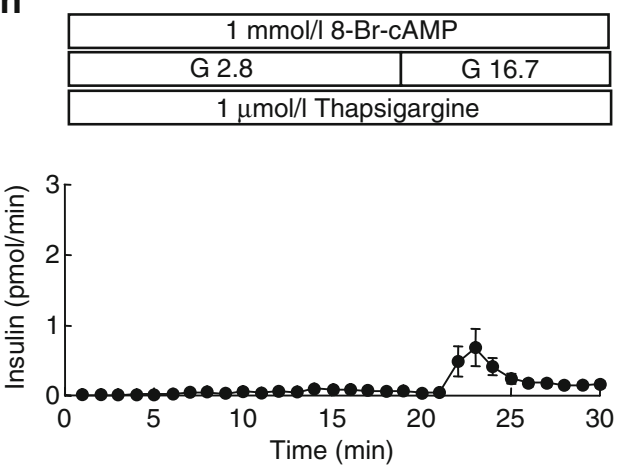

Kir6. $2^{-/}$mice Membrane depolarisation occurs through changes in the activity of ion channels and/or transporters in the beta cell membrane. cGMP-gated channels such as hyperpolarisation-activated cyclic nucleotide-modulated channels and cyclic nucleotide-gated channels are activated not only by cAMP but also by cGMP. To assess the possible involvement of these channels in membrane depolarisation, Kir6. $2^{-/-}$mouse pancreases were treated with a membrane-permeable cGMP analogue, 8-pCPTcGMP (at $1 \mathrm{mmol} / \mathrm{l}$ ), during pancreas perfusion. 8-pCPT-
cGMP failed to induce GSIS (Fig. 2a) in Kir6. $2^{-/}$mice. We then considered the involvement of the CFTR channel, which has been shown to be regulated by cAMP and ATP [15]. However, involvement of the CFTR channel was excluded, since mRNA transcripts of CFTR were not detected in MIN6 cells or mouse pancreatic islets by RTPCR [16] (Fig. 2b).

Membrane depolarisation occurs because of the influx of cations such as $\mathrm{Na}^{+}$or $\mathrm{Ca}^{2+}$ or because of the efflux of anions such as $\mathrm{Cl}^{-}$. To investigate the possible involvement 
Fig. 2 Involvement of cAMPactivated channels or non-selective cation channels in 8-Br-cAMP-induced GSIS. Insulin secretion from perfused pancreases of Kir6.2 $2^{--}$(black circles) or Kir6. $2^{+/+}$(white circles) mice is shown. G 2.8, glucose at $2.8 \mathrm{mmol} / 1$; G 16.7 , glucose at $16.7 \mathrm{mmol} / \mathrm{l}$. a No involvement of cGMP-gated channels in cAMP-induced GSIS of Kir6.2. $2^{--}$mice. b RT-PCR analysis detecting CFTR (upper panel) and HPRT (lower panel) as a control. As positive control for CFTR, the product from mouse intestinal cDNA was electrophoresed in the left lane. No product for CFTR was detected in MIN6 or islet cells. c, $\mathbf{d}$ Effect of $\mathrm{Na}^{+}$ removal on insulin secretory response in Kir6. $2^{-/}$mice (c) or Kir6.2 $2^{+/+}$mice (d). $\mathrm{Na}^{+}$in the perfusate was replaced with NMG. e Effect of SKF96365 on insulin secretory response in Kir6. $2^{-/}$mice. Means $\pm \mathrm{SE}$ of $n=3-8$ mice

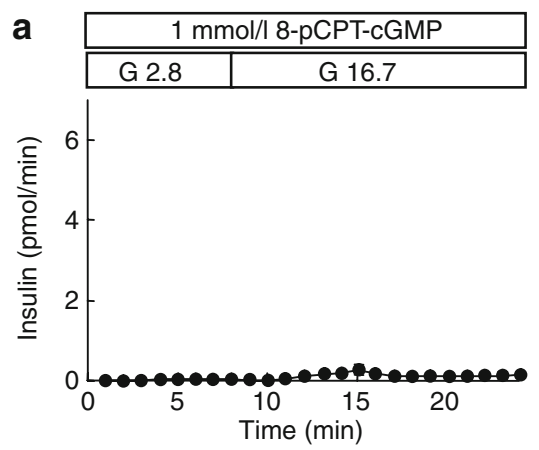

b
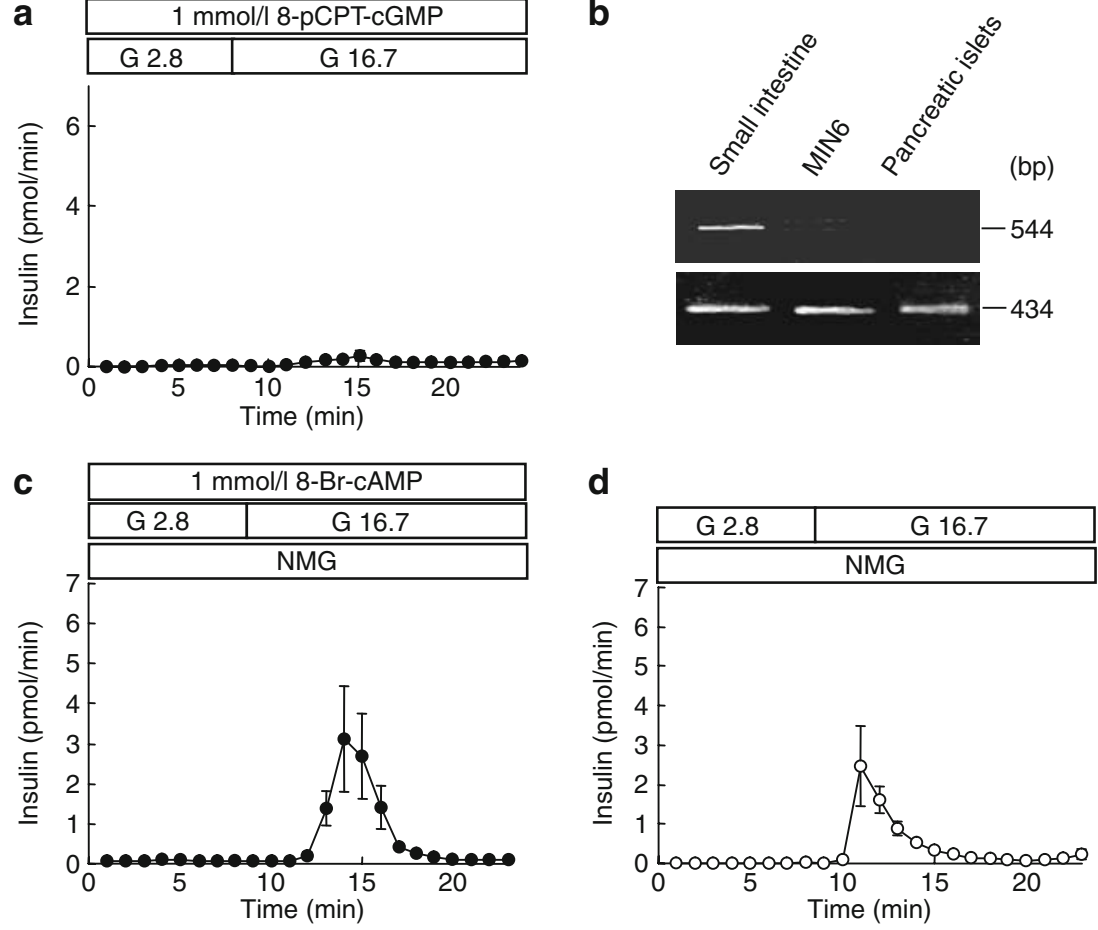

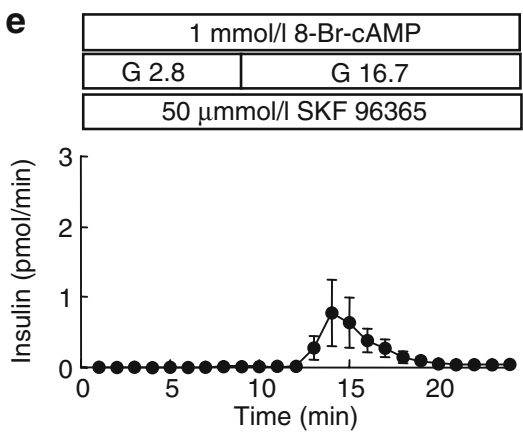

of $\mathrm{Na}^{+}$-permeable NSCCs in the potentiation of glucose responsiveness by cAMP, we repeated pancreas perfusion experiments under $\mathrm{Na}^{+}$-free conditions by replacing $\mathrm{Na}^{+}$in the perfusate with NMG. The removal of extracellular $\mathrm{Na}^{+}$ failed to suppress the early, first phase of GSIS in the presence of 8-Br-cAMP (Fig. 2c), indicating that $\mathrm{Na}^{+}$influx through NSCCs does not contribute to triggering GSIS by cAMP. On the other hand, the later, second phase of cAMPinduced GSIS was completely blocked by the removal of $\mathrm{Na}^{+}$. The role of $\mathrm{Na}^{+}$influx through NSCCs in the late phase of GSIS was also examined in Kir6. $2^{+/+}$mice. As was the case with Kir6. $2^{-/}$mice, the removal of $\mathrm{Na}^{+}$from the perfusate inhibited the late phase of GSIS in Kir6. $2^{+/+}$ mice (Fig. 2d). The second phase of cAMP-induced GSIS was also suppressed by treatment with SKF96365, a blocker of $\mathrm{Ca}^{2+}$-release-activated $\mathrm{Ca}^{2+}$ (CRAC) channels. However, unlike $\mathrm{NaN}_{3}$, SKF96365 did not delay the first phase of secretion in Kir6.2 $2^{-/}$mice (Fig. 2e). Together, these results strongly suggest that both $\mathrm{Na}^{+}$and $\mathrm{Ca}^{2+}$ influx through NSCC or CRAC channels are required for the maintenance of the late phase of GSIS, but are not required for the initial actions of cAMP in triggering insulin secretion.

cAMP-induced glucose responsiveness in Kir6. $2^{--}$mice is inhibited by niflumic acid and DPC We then considered the involvement of beta cell $\mathrm{Cl}^{-}$channels in cAMP-induced GSIS in Kir6. $2^{-/}$mice. We examined the effects of niflumic acid, which blocks beta cell anion channels [17], on the induction of GSIS by cAMP application. We found that the application of $100 \mu \mathrm{mol} / 1$ niflumic acid almost completely blocked cAMP-induced GSIS in Kir6. $2^{-/-}$ pancreases (Fig. 3a, d). On the other hand, treatment with a high concentration of $\mathrm{K}^{+}$was still capable of inducing a rapid insulin secretory response, demonstrating that the secretory apparatus of the cell was still competent.

To confirm that niflumic acid inhibits cAMP-induced GSIS by specifically reducing membrane excitability, the 
Fig. 3 Inhibition of GSIS by niflumic acid (a-d) or DPC (e) in Kir6. $2^{-/}$mice. G 2.8, glucose at $2.8 \mathrm{mmol} / \mathrm{l}$; G 16.7 , glucose at $16.7 \mathrm{mmol} / \mathrm{l}$. b-d Dose-dependent effects of niflumic acid (black circles, solid line) on cAMP-induced GSIS in Kir6. $2^{-/}$mice; $10 \mu \mathrm{mol} / \mathrm{l}$ (b), $50 \mu \mathrm{mol} / \mathrm{l}$ (c) and $100 \mu \mathrm{mol} / 1$ (d: magnification of a) niflumic acid was applied during the perfusion experiment. White circles with dotted lines are GSIS treated with $0 \mu \mathrm{mol} / 1$ niflumic acid, representing the secretion of Kir6. $2^{-/}$mice scaled up from the line in Fig. 1a. In Fig. 1a and e, the pancreases were perfused with the buffer containing $60 \mathrm{mmol} / 1 \mathrm{~K}^{+}$ $\left(60 \mathrm{mmol} / 1 \mathrm{~K}^{+}\right)$in the final step to confirm the viability of the pancreases. Means $\pm \mathrm{SE}$ of $n=3$ or 4 mice
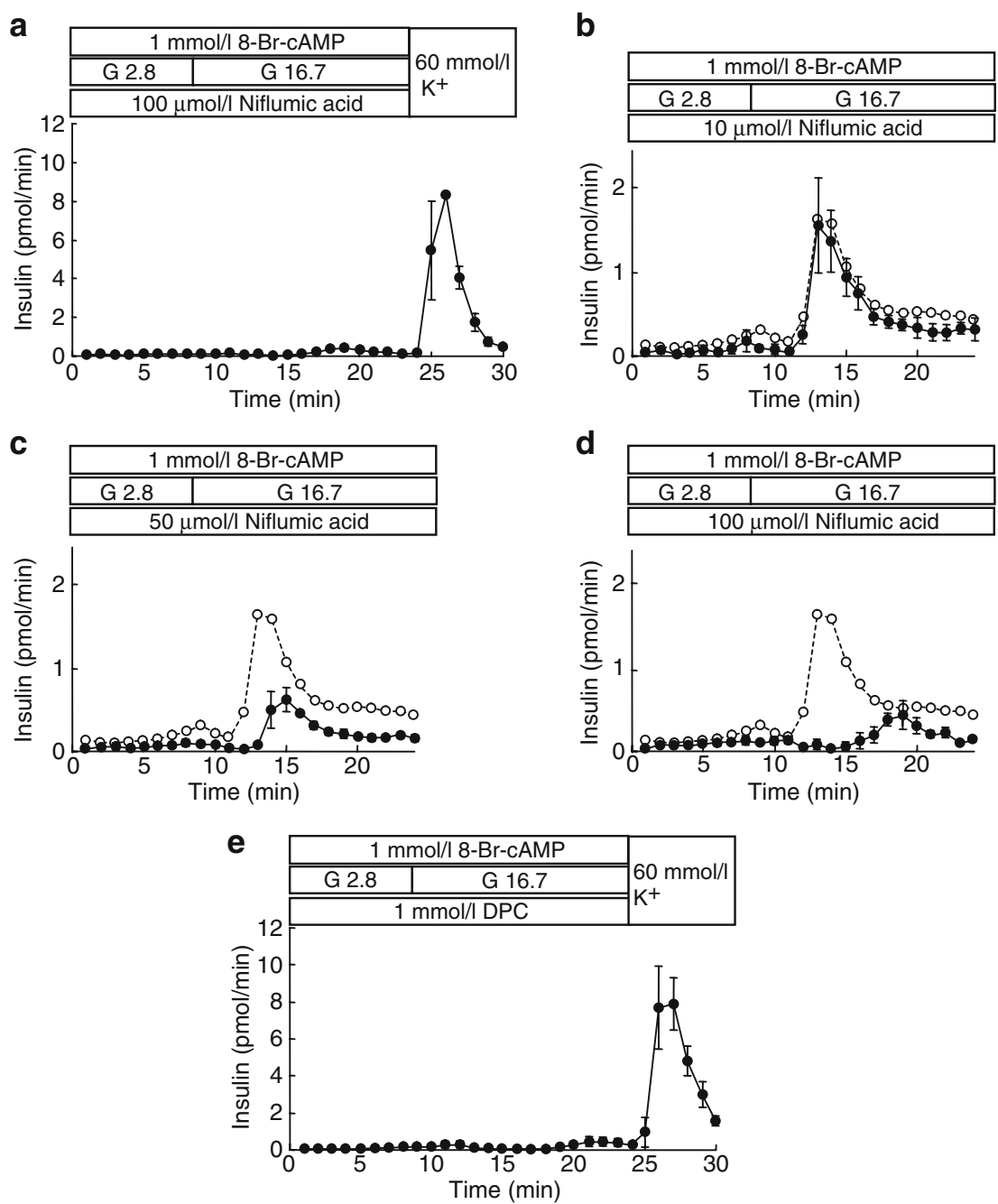

effects of different concentrations $(10 \mu \mathrm{mol} / \mathrm{l}$, Fig. 3b; $50 \mu \mathrm{mol} / \mathrm{l}, \mathrm{c})$ of niflumic acid were examined. Niflumic acid dose-dependently delayed the onset of secretion as well as decreasing the amount of secretion (Fig. 3b-d). In addition, DPC, another $\mathrm{Cl}^{-}$channel blocker, also blocked cAMP-induced glucose responsiveness in Kir6. $2^{-/}$mice without altering $\mathrm{KCl}$-induced insulin secretion (Fig. 3e).

Continuous firing of membrane potential spikes in Kir6. $2^{-/}$ beta cells To directly assess possible changes in cellular excitability of Kir6. $2^{-/-}$beta cells, we first attempted to assess the membrane potentials of pancreatic beta cells in Kir6. $2^{-/-}$islets in tissue culture. All of the cells examined to date (recorded from the cells in five islets isolated from Kir6. $2^{-/-}$mice) tended to show continuous firing from a depolarised membrane potential (data not shown), similar to previous results [7] obtained in cells cultured for $72 \mathrm{~h}$. Thus, a detailed investigation of the electrophysiological mechanisms of insulin secretion triggered by cAMP plus glucose was problematical in the pancreatic beta cells isolated from Kir6. $2^{-/}$mice and then cultured over several days.
cAMP and high glucose induce membrane depolarisation of $K_{A T P}$ channel-inactivated MIN6 cells As an alternative approach, we next examined changes in membrane potential induced by cAMP plus glucose in a pancreatic beta cell line, the MIN6 cell. Because of the measurement problem in Kir6. $2^{-/}$mice mentioned above, we used insulinsecreting MIN6 cells after functionally ablating their $\mathrm{K}_{\text {ATP }}$ channel activity by long-term exposure to the sulfonylurea glibenclamide [11]. The resting membrane potential of these $\mathrm{K}_{\text {ATP }}$ channel-inactivated MIN6 cells was found to be depolarised to about $-50 \mathrm{mV}$ (Fig. 4). MIN6 cells that failed to further depolarise in response to $16.7 \mathrm{mmol} / \mathrm{l}$ glucose were used for the following experiments. First, we examined the changes of membrane potential due to glucose plus cAMP in the glucose-unresponsive cells $(n=$ 7). We found that $K_{\text {ATP }}$ channel-inactivated MIN6 cells were slightly hyperpolarised in response to high glucose (Fig. 4a). When the membrane potentials of the 8-BrcAMP-treated cells were measured just before (as basal) and then $3 \mathrm{~min}$ after the glucose stimulation (as poststimulation), the membrane was found to be significantly 
a
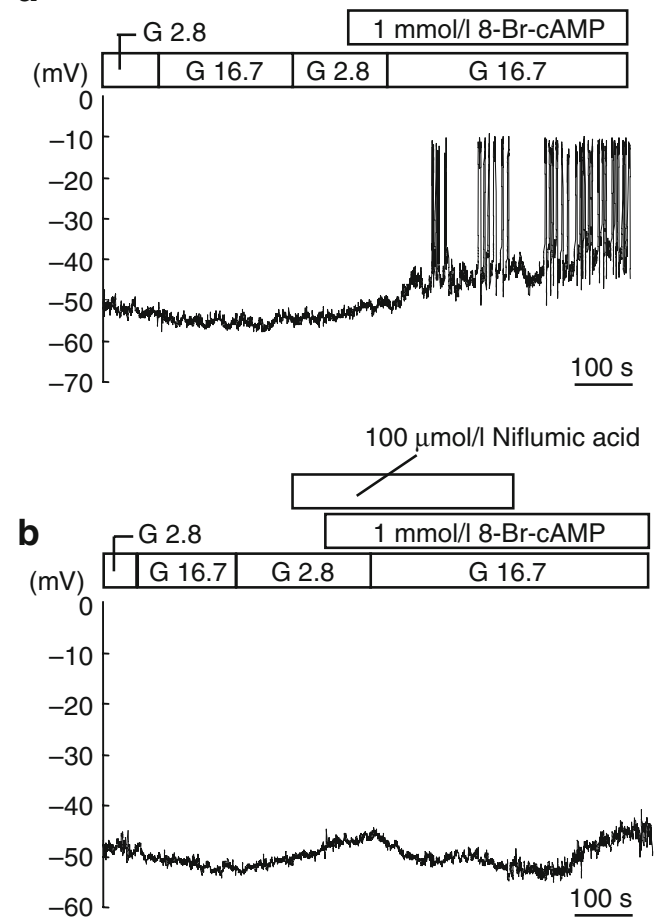

Fig. 4 Changes in membrane potentials in $\mathrm{K}_{\mathrm{ATP}}$ channel-inactivated MIN6 cells. G 2.8, glucose at $2.8 \mathrm{mmol} / 1 ; \mathrm{G} \mathrm{16.7,} \mathrm{glucose} \mathrm{at}$ $16.7 \mathrm{mmol} / \mathrm{l}$. a Membrane potentials in response to a high concentration of glucose in the absence and presence of $1 \mathrm{mmol} / 1$ 8-Br-cAMP. $\mathbf{b}$ Effect of niflumic acid on depolarisation by 8 -Br-cAMP plus a high concentration of glucose. Representative recordings are shown and similar results were obtained from independent experiments

hyperpolarised, from $-50.38 \pm 1.37$ to $-55.19 \pm 1.71 \mathrm{mV}$ ( $n=$ $7, p<0.0005)$ by the glucose stimulation. In contrast, treatment of these cells with $1 \mathrm{mmol} / 18$-Br-cAMP resulted in a gradual depolarisation of the membrane potential in response to $16.7 \mathrm{mmol} / \mathrm{l}$ glucose until irregular bursts of action potentials were observed in six out of seven cells examined (Fig. 4a). When the membrane potentials of these six cells were quantified by measurements made just before the glucose stimulation (as basal) and then just before the initiation of bursting (as post-stimulation), the membrane was now found to be significantly depolarised (from $-48.28 \pm 1.96$ to $-41.87 \pm 2.04 \mathrm{mV}, n=6, p<0.001)$ by glucose. The one remaining cell that did not exhibit bursts was also depolarised, but was excluded from the data since the lack of bursts made it more difficult for us to determine a consistent time point at which to measure the membrane potential. There was a relatively long time lag (about $2 \mathrm{~min}$ ) before the bursts commenced in response to $1 \mathrm{mmol} / 1 \mathrm{l}-\mathrm{Br}$-cAMP plus glucose, compared with control (glibenclamide-untreated) MIN6 cells (which fired within $20 \mathrm{~s}$, data not shown). These results suggest that the delay in insulin secretion induced by cAMP plus glucose in Kir6. $2^{-/}$mice (Fig. 1b) was most probably due to a slow, gradual membrane depolarisation produced by the stimuli.
We then examined six glucose-unresponsive, glibenclamide-treated MIN6 cells to analyse changes in membrane potential in the presence of $100 \mu \mathrm{mol} / 1$ niflumic acid. Measurement of membrane potentials made just before (as basal) and $3 \mathrm{~min}$ after glucose stimulation (as poststimulated) revealed that these cells failed to show induction of gradual membrane depolarisation by glucose plus cAMP (the potentials were changed from $-46.52 \pm 2.63$ to $-48.59 \pm 1.94 \mathrm{mV}, n=6$, not statistically significant), or any cell firing, in fact (Fig. 4b), clearly indicating that niflumic acid-sensitive channels are essential for membrane depolarisation induced by glucose plus cAMP in $\mathrm{K}_{\mathrm{ATP}}$ channel-inactivated MIN6 cells.

cAMP endows also normal pancreatic beta cells with responsiveness to small changes in glucose concentration Finally, we investigated the physiological relevance of the induction of glucose responsiveness by cAMP using a protocol in which we gradually increased the glucose concentration in a stepwise manner. In the absence of 8Br-cAMP, the pancreases of Kir $6.2^{+/+}$mice failed to secrete insulin in response to gradual, small stepwise increases $(1.4 \mathrm{mmol} / 1$ in every $5 \mathrm{~min})$ in the glucose concentration from 2.8 to $12.5 \mathrm{mmol} / \mathrm{l}$ (Fig. 5a). However, in the presence of 8-Br-cAMP (Fig. 5a), insulin secretion was readily evoked in response to these small increases in glucose concentration. Similar results were obtained when GLP-1 was substituted for 8-Br-cAMP (Fig. 5b). Insulin secretion in response to the small increases in glucose concentration in the presence of 8-Br-cAMP was also evoked in Kir6. $2^{-/}$ mice, with a delay of a few minutes (Fig. $5 \mathrm{c}$ ). In addition, in Kir6. $2^{+/+}$mice, niflumic acid treatment blocked the cAMP-induced secretory response to the stepwise increases in the glucose concentration (Fig. 5d). On the other hand, in response to a larger, more abrupt increase in glucose concentration (from 2.8 to $16.7 \mathrm{mmol} / \mathrm{l}$ ), 50 or $100 \mu \mathrm{mol} / \mathrm{l}$ niflumic acid did not significantly reduce first-phase insulin secretion in Kir6. $2^{+/+}$mice (Fig. 5e).

\section{Discussion}

We found that 8-Br-cAMP induces glucose responsiveness in Kir6. $2^{-/}$mice in a manner similar to that of the incretins, both of which elicit the secretion with a 1-2 min delay [10]. Regarding the mediator of glucose signalling, we found that ATP generated from glucose metabolism is required for the induction of GSIS by cAMP in the $\mathrm{K}_{\mathrm{ATP}}$ channel-deficient state, as $\mathrm{NaN}_{3}$, which blocks the last step of ATP production, suppressed secretion. Considering that $\mathrm{NaN}_{3}$ inhibits ATP synthesis in mitochondria but not in the cytosol (which occurs through glycolysis), a 
Fig. 5 Effect of cAMP on insulin secretion in response to a small rise and gradual increase in glucose concentration $(\mathrm{G}$, with values in $\mathrm{mmol} / \mathrm{l})$. $\mathbf{a}, \mathbf{b}$ Insulin response of Kir6. $2^{+/+}$ mice to small and stepwise increases (increments of $1.4 \mathrm{mmol} / \mathrm{l}$ ) in glucose concentration in the absence (white circles in a) and presence (white triangles in a) of $1 \mathrm{mmol} / 1 \mathrm{8}-\mathrm{Br}$ cAMP and $10 \mathrm{nmol} / 1 \mathrm{GLP}-1$ (b). c Insulin secretion in response to small and stepwise increases in glucose concentration in the presence of 8-Br-cAMP in Kir6. $2^{-/-}$mice (black circles). Data on Kir6. $2^{+/+}$mice (white triangles) are shown by dotted line for comparison. d Effect of niflumic acid on 8-Br-cAMPinduced glucose responsiveness (small and stepwise increases in glucose concentration) in Kir6. $2^{+/+}$mice. e Effect of 50 (squares) or 100 (triangles) $\mu \mathrm{mol} / \mathrm{l}$ niflumic acid on 8-BrcAMP-induced glucose responsiveness (a large and rapid increase in glucose concentration) in Kir6. $2^{+/+}$. For comparison, the insulin response in the absence of niflumic acid is shown (mean values from the data of Fig. 1b) (dotted line with white circles). Means \pm SE of $n=3-5$ mice a

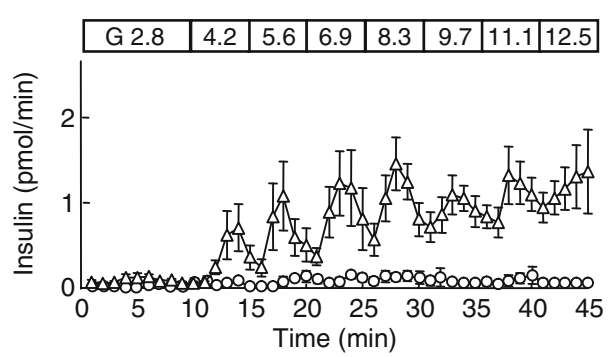

C

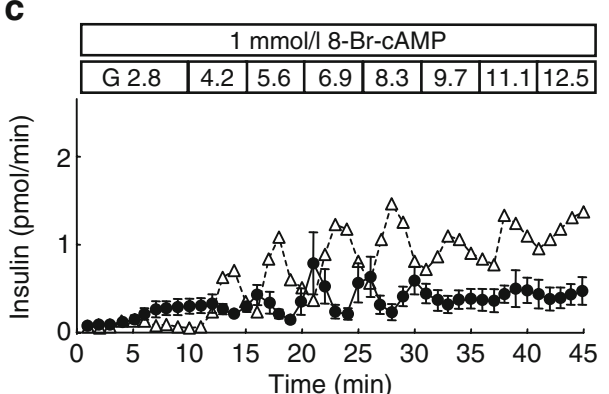

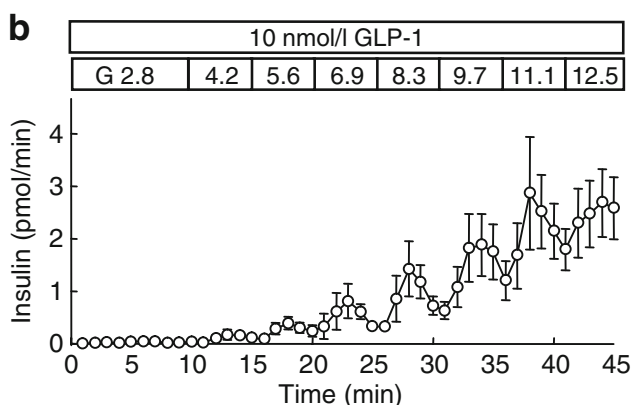

d
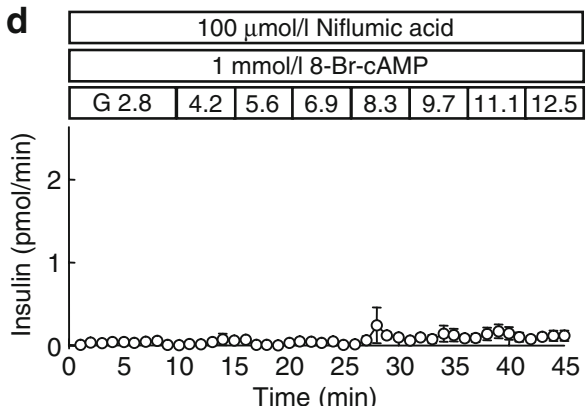

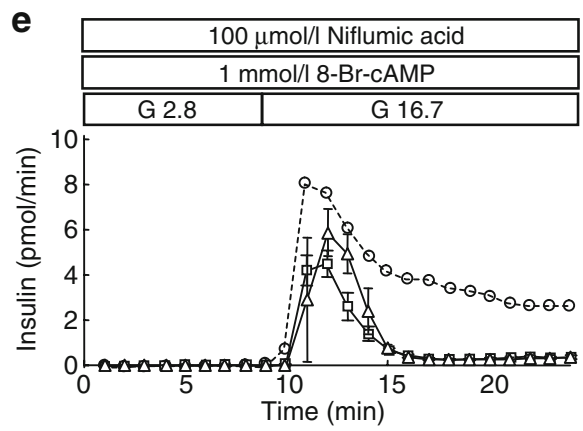

residual response observed in the presence of $\mathrm{NaN}_{3}$ seems reasonable.

Nifedipine completely abolished cAMP-induced GSIS, although thapsigargin failed to block it, indicating that membrane depolarisation mediated by the actions of ion channels or transporters, but not the intracellular $\mathrm{Ca}^{2+}$ release from the endoplasmic reticulum, is involved in the process. After screening several agonists and antagonists of channels and transporters, we found that treatment with niflumic acid or DPC completely abolished 8-Br-cAMP-induced GSIS in Kir6. $2^{-/}$mice. These findings suggest that the activation of islet $\mathrm{Cl}^{-}$channels by cAMP and ATP might help to depolarise the beta cell plasma membrane and elicit action potentials through activation of the VDCCs [15]. Since niflumic acid dose-dependently delayed the first phase and inhibited the second phase of cAMP-induced GSIS in Kir6. $2^{-/}$mice (Fig. 3 b-d), $\mathrm{Cl}^{-}$channel blockade probably contributes to both first- and second-phase insulin secretion in Kir6. $2^{-/-}$mice. In contrast, in Kir6. $2^{+/+}$mice, 50 or $100 \mu \mathrm{mol} / \mathrm{l}$ niflumic acid significantly reduced the second phase of insulin secretion, while only slightly decreasing the first phase (Fig. 5 e), suggesting that the $\mathrm{K}_{\mathrm{ATP}}$ channels of
Kir6. $2^{+/+}$mice mask the contribution of niflumic acidsensitive channels to the first phase of cAMP-induced GSIS. These results suggest that the mechanisms involved in inhibiting first- and second-phase secretion probably differ in Kir6. $2^{-/}$mice. While niflumic acid is often used to block $\mathrm{Cl}^{-}$channels, it is also known to target NSCCs such as transient receptor potential channels [18]. It remains unknown which of these channels specifically underlies the abolishment of cAMP-induced GSIS by niflumic acid since this was not investigated in the present study.

It has been reported that $\mathrm{Na}^{+}$influx through nonselective cation channels is essential for glucose-stimulated intracellular $\mathrm{Ca}^{2+}$ concentration oscillations and that either external $\mathrm{Na}^{+}$removal or the application of SKF96365, a blocker of CRAC channels, suppresses glucose-stimulated $\mathrm{Ca}^{2+}$ oscillations [19]. Our findings on the second phase of insulin secretion (Figs 2c-e and 5e) are consistent with the study [19]. Thus, activation of $\mathrm{Na}^{+}$influx, possibly through non-selective cation channels, may participate in the sustained cellular firing and the $\mathrm{Ca}^{2+}$ oscillations of beta cells, both of which are required for the sustained phase of insulin secretion. 
We previously reported that Kir $6.2^{-/}$beta cells showed continuous cell firing under unstimulated conditions [7]. However, the cells used for these recordings had been cultured for 2 days in RPMI medium. Recently, we and others found that the culture conditions greatly influence the cellular electrophysiological status [20]. We also found that the cultured islets of Kir6. $2^{-/}$mice exhibited markedly increased insulin secretion under basal conditions. We therefore used glibenclamide-treated MIN6 cells as a model system or surrogate for Kir6. $2^{-/}$beta cells, since we found that these cells have diminished $\mathrm{K}_{\text {ATP }}$ channel activity, diminished GSIS and relatively normal basal insulin secretion [11]. Treatment with 8-Br-cAMP plus glucose caused membrane depolarisation and subsequent bursts of action potentials in the glibenclamide-treated MIN6 cells, which were not depolarised by either glibenclamide or glucose alone. In addition, niflumic acid was found to completely block the depolarisation produced by cAMP plus glucose, and instead induced membrane hyperpolarisation, demonstrating that niflumic acid-sensitive channels participate in depolarisation under these conditions. We also examined the effect of cAMP plus glucose on membrane potential in the absence of extracellular $\mathrm{Na}^{+}$. Even under $\mathrm{Na}^{+}$-free condition, cAMP plus glucose caused membrane depolarisation.

It has been reported that cAMP activates ATP-sensitive $\mathrm{Cl}^{-}$channel currents in the HIT pancreatic beta cell line [15], and that glucose induces an increase in $\mathrm{Cl}^{-}$currents in isolated pancreatic beta cells [21]. Thus, it is reasonable to assume that niflumic acid-sensitive $\mathrm{Cl}^{-}$channels correspond to the ATP-sensitive $\mathrm{Cl}^{-}$channel previously reported [15]. We performed RT-PCR analysis of several known $\mathrm{Cl}^{-}$ channels (ClCn1-7, CLCA1-6, ClC-Ka and $\mathrm{Kb}$, Clns1a and CFTR) in Kir6. $2^{+/+}$islets and MIN6 cells (data not shown). Among these, $\mathrm{ClCn} 3,6$ and 7, $\mathrm{ClC}-\mathrm{Kb}$ and $\mathrm{Clns} 1 \mathrm{a}$ were found to be expressed in islets and MIN6 cells. However, $\mathrm{ClCn} 3,6$ and 7 are unlikely to be involved in cAMP-induced GSIS, as these channels exist primarily on the subcellular membrane. In addition, $\mathrm{ClC}-\mathrm{Kb}$ is insensitive to niflumic acid [22]. Since Clns1a is considered to comprise volume-sensitive $\mathrm{Cl}^{-}$channels [23], Clns1a may well participate in membrane depolarisation of the pancreatic beta cells in response to cAMP plus glucose.

To clarify the role of cAMP in GSIS under physiological conditions, we gradually increased the glucose concentration in a stepwise manner in the presence or absence of cAMP. Interestingly, a small increase in the glucose concentration failed to trigger insulin secretion in the absence of 8-Br-cAMP or GLP-1, but dramatically evoked insulin secretion in their presence. Such GSIS was almost completely abolished by treatment with niflumic acid. These findings demonstrate that cAMP is critical in inducing the insulin response to small increases in glucose concentration by activating niflumic acid-sensitive chan- nels, while the insulin response to large increases in glucose concentration in the presence of cAMP depends mostly on the activity of $\mathrm{K}_{\mathrm{ATP}}$ channels. These data also demonstrate that GSIS is triggered not only by absolute levels of glucose but also by incremental changes in glucose concentration. In contrast, in vivo human studies have shown a proportional relationship between blood glucose levels and serum insulin levels under protocols using low-dosage, graded intravenous glucose infusions [24, 25]. The discrepancy between the in vivo experiments in humans and our mouse perfusion experiments may be due to the different experimental protocols used. In human clamp studies performed in vivo, as glucose is infused systemically, insulin secretion may be influenced by hormonal and/or neuronal regulation. Doliba et al. reported that when the glucose concentration was increased progressively from 0 to $30 \mathrm{mmol} / 1$ in perifused islets of Kir6. $2^{+/+}$mice, insulin secretion was stimulated in a dose-dependent manner [26]. However, the rate of increase in glucose concentration $\left(0.8 \mathrm{mmol} \mathrm{l}^{-1} \mathrm{~min}^{-1}\right)$ was much higher than that used in the present study $\left(1.4 \mathrm{mmol} \mathrm{l}^{-1}\right.$ $5 \mathrm{~min}^{-1}$ ), suggesting that a smaller rate of increase in glucose concentration may be the crucial factor in triggering GSIS.

GLP-1 treatment has been reported to restore the glucoseresponsiveness of insulin secretion in type 2 diabetes patients whose pancreas has lost significant glucose responsiveness [27]. The mechanism is related to the finding that GLP-1 renders glucose resistant cells 'glucose-competent', probably by modulating $\mathrm{K}_{\mathrm{ATP}}$ channel activity [28]. Our study demonstrates that GLP-1, which triggers cAMP signalling in beta cells, evokes glucose responsiveness also by activating niflumic acid-sensitive channels which can also depolarise the beta cell plasma membrane.

Considering that blood glucose concentrations increase gradually after meal ingestion, ranging from $4-5$ to $<8.0 \mathrm{mmol} / \mathrm{l}$ [29] with concomitant rises in the plasma concentration of the incretins, the induction of GSIS by cAMP may have an important role in maintaining the blood glucose level within the physiological range.

Acknowledgements This work was supported by Grants-in-Aid for Specially Promoted Research (15002002) and scientific research grants from the Ministry of Education, Culture, Sports, Science and Technology, by a grant from CREST (Core Research for Evolutional Science and Technology), by a grant from the Global Center for Education and Research in Integrative Membrane Biology, Japan, and by a grant from the National Institutes of Health of the USA (RO1DK46409 to L. Satin).

Duality of interest The authors declare that there is no duality of interest associated with this manuscript.

\section{References}

1. Henquin JC (2000) Triggering and amplifying pathways of regulation of insulin secretion by glucose. Diabetes 49:1751-1760 
2. MacDonald PE, Joseph JW, Rorsman P (2005) Glucose-sensing mechanisms in pancreatic beta-cells. Philos Trans R Soc Lond B Biol Sci 360:2211-2225

3. Miki T, Seino S (2005) Roles of $\mathrm{K}_{\mathrm{ATP}}$ channels as metabolic sensors in acute metabolic changes. J Mol Cell Cardiol 38:917925

4. Holst JJ, Gromada J (2004) Role of incretin hormones in the regulation of insulin secretion in diabetic and nondiabetic humans. Am J Physiol Endocrinol Metab 287:E199-E206

5. Drucker DJ (2006) The biology of incretin hormones. Cell Metab 3:153-165

6. Weir GC, Mojsov S, Hendrick GK, Habener JF (1989) Glucagonlike peptide I (7-37) actions on endocrine pancreas. Diabetes 38:338-342

7. Miki T, Nagashima K, Tashiro F et al (1998) Defective insulin secretion and enhanced insulin action in $\mathrm{K}_{\mathrm{ATP}}$ channel-deficient mice. Proc Natl Acad Sci USA 95:10402-10406

8. Seghers V, Nakazaki M, DeMayo F, Aguilar-Bryan L, Bryan J (2000) Surl knockout mice. A model for $\mathrm{K}_{\text {ATP }}$ channelindependent regulation of insulin secretion. J Biol Chem 275: 9270-9277

9. Shiota C, Larsson O, Shelton KD et al (2002) Sulfonylurea receptor type 1 knock-out mice have intact feeding-stimulated insulin secretion despite marked impairment in their response to glucose. J Biol Chem 277:37176-37183

10. Miki T, Minami K, Shinozaki H et al (2005) Distinct effects of glucose-dependent insulinotropic polypeptide and glucagon-like peptide-1 on insulin secretion and gut motility. Diabetes 54:10561063

11. Kawaki J, Nagashima K, Tanaka J et al (1999) Unresponsiveness to glibenclamide during chronic treatment induced by reduction of ATP-sensitive $\mathrm{K}^{+}$channel activity. Diabetes 48:2001-2006

12. Ishihara H, Maechler P, Gjinovci A, Herrera PL, Wollheim CB (2003) Islet beta-cell secretion determines glucagon release from neighbouring alpha-cells. Nat Cell Biol 5:330-335

13. Roe MW, Mertz RJ, Lancaster ME, Worley JF 3rd, Dukes ID (1994) Thapsigargin inhibits the glucose-induced decrease of intracellular $\mathrm{Ca}^{2+}$ in mouse islets of Langerhans. Am J Physiol 266:E852-E862

14. Worley JF 3rd, McIntyre MS, Spencer B, Dukes ID (1994) Depletion of intracellular $\mathrm{Ca}^{2+}$ stores activates a maitotoxinsensitive nonselective cationic current in beta-cells. J Biol Chem 269:32055-32058

15. Kinard TA, Satin LS (1995) An ATP-sensitive $\mathrm{Cl}^{-}$channel current that is activated by cell swelling, cAMP, and glyburide in insulinsecreting cells. Diabetes 44:1461-1466
16. Stalvey MS, Muller C, Schatz DA et al (2006) Cystic fibrosis transmembrane conductance regulator deficiency exacerbates islet cell dysfunction after beta-cell injury. Diabetes 55:1939-1945

17. Jentsch TJ, Stein V, Weinreich F, Zdebik AA (2002) Molecular structure and physiological function of chloride channels. Physiol Rev 82:503-568

18. Poronnik P, Ward MC, Cook DI (1992) Intracellular $\mathrm{Ca}^{2+}$ release by flufenamic acid and other blockers of the non-selective cation channel. FEBS Lett 296:245-248

19. Roe MW, Worley JF 3rd, Qian F et al (1998) Characterization of a $\mathrm{Ca}^{2+}$ release-activated nonselective cation current regulating membrane potential and $\left[\mathrm{Ca}^{2+}\right]_{i}$ oscillations in transgenically derived beta-cells. J Biol Chem 273:10402-10410

20. Szollosi A, Nenquin M, Henquin JC (2007) Overnight culture unmasks glucose-induced insulin secretion in mouse islets lacking ATP-sensitive $\mathrm{K}^{+}$channels by improving the triggering $\mathrm{Ca}^{2+}$ signal. J Biol Chem. 282:14768-14776

21. Best L (2002) Study of a glucose-activated anion-selective channel in rat pancreatic beta-cells. Pflugers Arch 445:97-104

22. Liantonio A, Picollo A, Babini E et al (2006) Activation and inhibition of kidney CLC-K chloride channels by fenamates. Mol Pharmacol 69:165-173

23. Ritter M, Ravasio A, Jakab M et al (2003) Cell swelling stimulates cytosol to membrane transposition of ICln. J Biol Chem 278:50163-50174

24. Byrne MM, Sturis J, Clément K et al (1994) Insulin secretory abnormalities in subjects with hyperglycemia due to glucokinase mutations. J Clin Invest 93:1120-1130

25. Byrne MM, Sturis J, Polonsky KS (1995) Insulin secretion and clearance during low-dose graded glucose infusion. Am J Physiol 268:E21-E27

26. Doliba NM, Qin W, Vatamaniuk MZ et al (2004) Restitution of defective glucose-stimulated insulin release of sulfonylurea type 1 receptor knockout mice by acetylcholine. Am J Physiol Endocrinol Metab 286:E834-E843

27. Nauck MA, Heimesaat MM, Orskov C, Holst JJ, Ebert R, Creutzfeldt W (1993) Preserved incretin activity of glucagon-like peptide 1 [7-36 amide] but not of synthetic human gastric inhibitory polypeptide in patients with type- 2 diabetes mellitus. J Clin Invest 91:301-307

28. Holz GG 4th, Kuhtreiber WM, Habener JF (1993) Pancreatic beta-cells are rendered glucose-competent by the insulinotropic hormone glucagon-like peptide-1(7-37). Nature 361:362-365

29. Suzuki H, Fukushima M, Okamoto $S$ et al (2005) Effects of thorough mastication on postprandial plasma glucose concentrations in nonobese Japanese subjects. Metabolism 54:1593-1599 